\title{
A APLICAÇÃO DA TERAPIA SOCIAL EMANCIPADORA ENQUANTO ALTERNATIVA À CRISE DO SISTEMA CARCERÁRIO NORTE-RIO- GRANDENSE: UM ENSAIO SOBRE A APAC E A JUSTIÇA RESTAURATIVA
}

\section{* Tallita de Carvalho Martins}

\section{RESUMO}

Trata sobre a ideologia da ressocialização e da reintegração social do apenado no contexto de crise vivenciado pelo sistema carcerário norte-rio-grandense. Metodologicamente, aponta revisão bibliográfica com análise crítica sobre a questão em deslinde, partindo de estudo de campo em visita às instalações da Associação de Proteção e Assistência ao Condenado (APAC) da cidade de Macau/RN, a fim de observar e discutir parâmetros mais efetivos voltados à solução da problemática em tela, debatendo, nesse cenário, sobre a Terapia Social Emancipadora e a implantação de um modelo de justiça restaurativa no estado.

Palavras-chave: Ressocialização. Reintegração. Terapia social emancipadora. APAC. Justiça restaurativa.

\section{THE APPLICATION OF EMANCIPATING SOCIAL THERAPY AS AN ALTERNATIVE TO THE CRISIS OF THE NORTH RIO GRANDENSE Jail System: A TEST ON APAC AND RESTAURANT JUSTICE}

\begin{abstract}
It deals with the ideology of resocialization and social reintegration of the inmate in the context of crisis experienced by the prison system in Rio Grande do Norte. Methodologically, it points out a bibliographic review with critical analysis on the slant issue, starting from a field study visiting the premises of the Association of Protection and Assistance to the Convict (APAC) of the city of Macau / RN, in order to observe and discuss more effective parameters. focused on solving the problem at hand, debating, in this scenario, about the Emancipatory Social Therapy and the implementation of a restorative justice model in the state.
\end{abstract}

Keywords: Resocialization. Reintegration. Emancipatory social therapy. APAC. Restorative Justice.

\section{INTRODUÇÃO}

Sob o contexto de falência concernente à ideologia da ressocialização no âmbito do Direito Penal brasileiro, o presente artigo objetiva tecer críticas acerca da função social da

\footnotetext{
* Advogada. Bacharela em Direito pela Universidade Federal do Rio Grande do Norte (UFRN). Mestranda em Direito Constitucional também pela UFRN. E-mail: martinstallita@gmail.com.
} 
pena, discutir a crise que rotineiramente vem afetando o sistema carcerário norte-riograndense e, nessa senda, dialogar acerca de métodos de reintegração social do apenado.

Atualmente, uma política criminal arrojada deve buscar a reinserção do preso na sociedade civil, a qual só pode ser alcançada com êxito mediante a humanização do regime de cumprimento da pena por intermédio de um mecanismo de saber integrado pautado na interdisciplinaridade.

Posto isso, a essência do trabalho em tela tem como foco esclarecer o verdadeiro desígnio da pena, destacando-se os pontos de debilidade da referida ideologia (da ressocialização) e, com isso, apontar possíveis saídas para a crise vivenciada neste cenário.

Assim sendo, apresentar-se-á a concepção em torno da terapia social emancipadora enquanto alternativa à falência de tal instituto, juntamente à proposta de implantação de um modelo de justiça restaurativa, que já vem sendo desenvolvido, capaz de reconstruir os laços rompidos entre o preso e a sociedade.

Destarte, abordar-se-á a viabilidade de expansão das Associações de Proteção e Assistência aos Condenados (APACs) no estado, expondo-se uma reflexão capaz de incutir mudanças de paradigma, analisando-se a imagem do apenado de um lado e, por outro ângulo, o processo de empoderamento da própria comunidade em relação ao sistema carcerário que lhe é afeito, abarcando-se a pragmatização de medidas efetivamente necessárias ao abrandamento do problema ora discutido.

Portanto, em detrimento a ideologias falhas e inadequadas, apresentadas como alternativas ao controle de criminalidade, o estudo ora em pauta busca evidenciar ideais mais sutis, mas que podem efetivamente surtir algum efeito positivo diante do quadro de calamidade instaurado no sistema carcerário norte-rio-grandense.

Desta feita, metodologicamente, o trabalho foi desenvolvido a partir de uma revisitação bibliográfica acerca de importantes estudos concernentes à criminologia crítica no que se refere aos desígnios da pena, como ponto de partida para implementação da terapia social emancipadora. Nesse contexto, realizou-se visita à APAC sediada em Macau/RN, analisando-se a realidade deste núcleo em face a dados estatísticos referentes à superpopulação carcerária do Rio Grande do Norte. 


\section{A DERROCADA DA IDEOLOGIA DA RESSOCIALIZAÇÃO ENQUANTO POSSIBILIDADE DE ASCENSÃO PARA A TERAPIA SOCIAL EMANCIPADORA}

Iniciando a discussão no tocante à teoria da prevenção especial positiva, que consubstancia a ideologia da ressocialização, de pronto é possível se considerar a premissa básica de que a reeducação do delinquente tem sido encarada como o fim principal da pena de prisão, ao mesmo tempo em que sofre duras críticas a respeito da sua crise de legitimidade no cenário político-criminal do país.

Tanto é válida a premissa sustentada pela ideologia em questão que a maioria dos modelos penitenciários existentes atualmente trazem à baila os preceitos que vinculam o sistema carcerário a esse objetivo. Exemplo disso se tem com a Lei Geral Penitenciária Espanhola, de 1979 (MUÑOZ CONDE; HASSEMER, 2008, p. 179) e também com as Regras Mínimas da ONU (Organização das Nações Unidas), por seu turno incorporadas pela Lei de Execução Penal brasileira.

Assim, necessário se faz explicar como a ideologia da ressocialização foi se fragilizando ao longo do tempo e qual a sua importância hodiernamente para o sistema penal. Para alguns teóricos, a exemplo de Santiago (1989), Muñoz Conde e Hassemer (2008), tratase de um conceito polêmico, mas não superado.

Por outro lado, adeptos à criminologia crítica, como Baratta (2016), seguindo por Alvino de Sá (2007), preferem o termo "reintegração social" em detrimento à "ressocialização", posto que associam este último conceito a uma ideia de tratamento e readaptação do preso, o qual é enxergado como sujeito passivo na sua reinserção social, sem que a sociedade atue ativamente nesse processo, ignorando sua parcela de culpa no problema.

Seguindo incialmente com a análise de Santiago (1989, p. 38), tem-se uma crise de legitimidade de caráter prático em torno da política ideológica em questão. $\mathrm{O}$ autor trabalha com a ideia de programas máximos e mínimos de ressocialização, problematizando o fato de que para se alcançar os fins propostos por tal concepção, faz-se necessário limitar suas pretensões e aumentar os seus meios de concretização.

Enquanto programas máximos de ressocialização, entende-se, por exemplo, o propósito de promover um convencimento ético ao apenado, fazendo-o internalizar valores sociais axiomáticos. Por óbvio, tal pretensão se torna uma "falácia idealista", impossível de 
ser alcançada dentro de uma estrutura que foi construída para promover a segregação e a manutenção do status quo daqueles que detém o poder.

Recuperando o raciocínio de Muñoz Conde e Hassemer (2008, p. 198), é possível concluir que "a sociedade necessita da estigmatização dos desviados para sua automanutenção e que toda infração normativa e sua conseguinte sanção confirmam e rebustecem as normas básicas para continuidade do grupo e da sociedade".

Desse modo, seguir um projeto de ressocialização pautado em tamanha aspiração, sem antes se desconstruir ou remodelar a própria sociedade, promotora de estigmas e desigualdade, remonta a uma "norma impossível", contrafactora, a qual simplesmente não pode ser concretizada (BARATTA, 2016).

Conforme coloca Bitencourt (2012, p. 152), “os pressupostos sobre os quais se apoiam as medidas de ressocialização são imprecisos, as técnicas de prognóstico são mutáveis e inseguras, sem que até hoje se haja demonstrado a eficácia empírica do fim reeducacional”.

Trazendo a análise para o panorama do sistema carcerário norte-rio-grandense, impor um programa máximo de ressocialização seria esperar que o agente criminoso, em grande escala, produto de um regime segregacional por essência, uma vez ingresso em um presídio similar à penitenciária de Alcaçuz, a qual atua com uma superlotação de mais de $80 \%$ da sua capacidade (BARBOSA, 2016), nutrindo mais violência, inclusive contra os seus direitos mais básicos, conseguisse, por si só, afastar-se da criminalização que lhe foi imposta.

Noutro pórtico, tão grave é a referida crise de legitimidade dessa ideologia que, mesmo em face a um sistema prisional planejado de acordo com parâmetros propiciadores da reeducação, com assistência material, médica e psicológica, empiricamente é impossível comprovar a efetividade de tal política, relembrando a observação supramencionada de Bitencourt (2012, p. 152).

Por essa razão, é crucial insistir na ideia de que, em um sistema projetado para a segregação, não se pode querer cumprir um fim ressocializador. Pois, em vez de resultados efetivos, ter-se-á uma ideologia desconectada do plano fático que de nada serve à resolução do problema em tela.

Dito isto, Santiago (1989, p. 39-40) chama atenção para a premência de se desenvolver programas mínimos de ressocialização, sem grandes ambições, basicamente voltados para a promoção de uma vida futura sem delitos. Apresentando-se, assim, a 


\section{A APLICAÇÃO DA TERAPIA SOCIAL EMANCIPADORA ENQUANTO ALTERNATIVA À CRISE DO \\ SISTEMA CARCERÁRIO NORTE-RIO-GRANDENSE: \\ UM ENSAIO SOBRE A APAC E A JUSTIÇA RESTAURATIVA}

ampliação de medidas alternativas à prisão e, quando inviável, uma execução penal que respeite a dignidade do presidiário e se oponha à "dessocialização" suscitada pelo cárcere.

Além disso, para que tal filosofia venha a lograr êxito, faz-se primordial reconhecer que nem sempre a ressocialização será possível, ainda que pensada com um conteúdo mínimo e de forma aberta. Mas, de toda maneira, deverá ser tentada, na medida do viável, não se renegando a segundo plano pelas dificuldades apresentadas.

Em certo ponto, a análise crítica proposta por Mir Puig Santiago (1989) aproxima-se bastante a de Baratta, sobretudo no que diz respeito ao fato de que o delinquente não precisa de "tratamento". Portanto, endossar o discurso da ressocialização não significa retomar uma ideologia de fim correcional.

Ainda de acordo com Baratta (1990): “O conceito de reintegração social requer a abertura de um processo de interações entre o cárcere e a sociedade, no qual os cidadãos recolhidos no cárcere se reconheçam na sociedade externa e a sociedade externa se reconheça no cárcere".

Trata-se, pois, de um processo de conscientização mútuo e voltado para o futuro, no qual não se visa uma "re-adequação" ética ou de conduta. A integração social recai sobre as possibilidades do interno de organizar o seu destino fora do cárcere, focando no que pode ser feito dali em diante, com base na sua própria força construtiva, mesmo diante dos limites existentes (SÁ, 2007).

Dessa maneira, o que se pode entender como fim terapêutico da ressocialização, para o estudo em tela, relaciona-se com o conceito de terapia social emancipadora, sustentada por autores da doutrina alemã, Haffke e Stratenwerth, desde a década de 1970 (MUÑOZ CONDE; HASSEMER, 2008, p. 191). Mais uma vez importante destacar que esta não se confunde com a ideologia de tratamento forçado, a qual claramente não logra êxito; ao invés disso, consiste na reestruturação do sistema para que se passe a compreender a pena como uma ajuda e não como um mal, oferecendo-se ao detento possibilidades de se recuperar.

Por seu turno, remete-se a um processo composto pelas mais diversas variantes, no qual inúmeros questionamentos devem ser levados em consideração, a fim de não se recair na crise de legitimidade que reflete as frequentes críticas à ressocialização.

Alinhando esse raciocínio às concepções de Zaffaroni (2015, p. 317), o cerne da questão diz respeito à mudança de autopercepção do presidiário, uma "revalorização" fundamental para expulsar o estereótipo introjetado pelo próprio sistema. Tem-se, pois, uma 
clínica de vulnerabilidades que, diferente da "criminogênese" individual, busca refletir sobre a "prisiogênese".

Vê-se, com isso, a obrigatoriedade de haver uma mudança de discurso e, acima de tudo, a necessidade de se implementar meios capazes de aplicá-lo no plano prático. Certamente não seria a panaceia para a crise do sistema carcerário, até porque tal teoria, assim como qualquer outra, não deve ser levada a extremo absoluto, mas, de toda forma, serviria enquanto caminho a ser traçado em face a um cenário de verdadeira escassez de soluções.

Isso porque, o colapso do sistema carcerário norte-rio-grandense atingiu um nível de conflituosidade que exige dos gestores, e da própria sociedade, a confluência de esforços na resolução do transtorno conflagrado nesse ambiente.

Logo, considerando a ineficácia das medidas então vigentes no respectivo cenário, torna-se impositiva a tarefa de se discutir alternativas mais humanas e efetivas à elucidação desse problema.

Nesse desiderato, vem-se falar em um novo modelo de gestão do sistema prisional, centrado na Associação de Proteção e Assistência ao Condenado (APAC), que traz ao plano prático a aplicação da "teoria social emancipadora", ressaltado anteriormente.

Sob a filosofia "Matar o criminoso e salvar o homem", a Associação de Proteção e Assistência ao Condenado se apresenta como medida realmente factível à reintegração social do preso, dentro dos devidos parâmetros de abordagem, os quais, cumpre salientar, não se confundem com os "programas máximos de ressocialização" apontados por Puig Santiago e já discutidos neste estudo (FBAC, 2016).

Trata-se de uma verdadeira coordenação de esforços, mediante o trabalho de voluntários treinados pelo próprio projeto, os quais participam de cursos de formação, passando por estágios com o desenvolvimento periódico de aulas de valorização humana, de espiritualidade e prevenção às drogas (FBAC, 2016).

Logo, ainda que se argumente a favor da inaplicabilidade desse projeto em larga escala para todos os perfis de condenados, há de concluir que os crimes mais ignóbeis e os quais de fato chocam a opinião pública, a exemplo de extermínios em massa, homicídios qualificados, dentre outros, são a minoria dos delitos cometidos na realidade do estado e do país, como um todo.

De acordo com levantamento de dados realizado pelo Ministério da Justiça em 2013, à medida que o índice de homens presos, no Brasil, pelos crimes de roubo, tráfico e furto 


\section{A APLICAÇÃO DA TERAPIA SOCIAL EMANCIPADORA ENQUANTO ALTERNATIVA À CRISE DO \\ SISTEMA CARCERÁRIO NORTE-RIO-GRANDENSE: \\ UM ENSAIO SOBRE A APAC E A JUSTIÇA RESTAURATIVA}

somam cerca de $64 \%$ dos delitos, o homicídio não ultrapassa a faixa dos $12 \%$. Entre as mulheres, o tráfico de entorpecentes chega ao patamar de $45 \%$, enquanto o homicídio se encontra entre a faixa dos $10 \%$ aos $15 \%$ (CONECTAS, 2014).

Além disso, segundo o Conselho Nacional de Justiça (CNJ), enquanto no sistema penitenciário comum 70\% dos egressos voltam a cometer crimes, na APAC esse índice não ultrapassa os 15\% (MARTINO, 2014). Por sua vez, esses resultados devem-se à linha de planejamento traçada pelo método "apaqueano", instituido por Mário Ottoboni, pautado em elementos que, conjugados harmoniosamente, refletem respostas positivas. São eles: participação na comunidade; trabalho; religião; assistência jurídica; assistência à saúde; valorização humana e famíliar (OTTOBONI, 2001).

A título de ilustração, o Centro de Reintegração Social (CRS) da APAC possibilita aos recuperandos dos diversos regimes cumprirem a pena próximo a seu núcleo afetivo e familiar, respeitando-se, com isso, as inter-relações sociais do preso e, consequentemente, promovendo-se um estímulo no seu processo pessoal de libertação (OTTOBONI, 2001).

Consoante ao que se prega com a teoria social emancipadora, o processo de reintegração, de acordo com a metodologia da APAC, consiste em uma autocrítica por parte do interno, levando-o a refletir sobre a possibilidade dele próprio atuar como agente da sua transformação, uma vez que tenha acesso aos mecanismos necessários para tanto. Nessa toada, a interdisciplinaridade, interligando saberes pertinentes à Psicologia, Psicanálise e, inclusive, à Teologia, consiste em condição indispensável no seu "tratamento" "

Nesse mesmo sentido coloca-se em pauta o conceito trabalhado em torno da Criminologia Clínica, enquanto ciência interdisciplinar, de acordo com a qual o comportamento do criminoso será analisado conforme estratégias de intervenção pensadas conjuntamente com o encarcerado. Desse modo, a execução da pena envolverá pessoas direta ou indiretamente relacionadas com o preso, de modo que se procurará conhecê-lo enquanto individuo, bem como todas as motivações que o levaram a desencadear tal conduta criminosa (SÁ, 2007).

Sob outro ângulo, o que se prega com tais modelos alternativos à lógica prisional instituída é o "direito de não se cometer novos crimes" (OTTOBONI, 2004). Pois, não há como esperar uma pronta reinserção de alguém que esteve durante anos ociosamente

\footnotetext{
${ }^{\dagger}$ Deve-se levar em conta que não se trata de um tratamento forçado, consoante analisado anteriormente.
} 
encarcerado sem tê-lo proporcionado os meios necessários para uma autossubsistência fora da prisão, onde carregará consigo o danoso estigma decorrente do seu aprisionamento.

Nesse sentido, o Estado precisa providenciar um ambiente externo de recepção do presidiário que internamente já esteja apto para voltar ao convívio em sociedade. Do contrário, torna-se impossível desconstruir os altos índices de reincidência criminal no país.

A titulo de ilustração, na trama dirigida por Frank Darabont, "Um sonho de liberdade", o personagem vivido por James Whitmore, Brooks Hatlen, depois de passar anos na prisão e ser solto, simplesmente não consegue se adaptar à liberdade que lhe foi forçada. Não há mais vínculos familiares ou afetivos a serem recuperados e tudo o que lhe restava, resultado de um processo de "prisionalização", desaparece quando ele é excretado do sistema. Desse modo, não conseguindo se readaptar, Brooks se suicida.

Nada obstante seja esta uma história fictícia interpretada pela dramaturgia, em muito "a vida imita a arte" nesse aspecto. Por essa razão, enquanto não se proporcionar um "direito de não se cometer novos crimes" (OTTOBONI, 2004), o condenado não recuperado estará fadado a reproduzir a violência assimilada.

Por outro lado, a efetividade em um tratamento digno ao presidiário pode ser percebida de forma inconteste, bastando se ter um mínimo conhecimento sobre o assunto, comparando-se, por exemplo, o modelo disseminado pela APAC com a realidade do sistema prisional comum. No entanto, pouco se debate sobre a temática, até mesmo no meio acadêmico, o que dificulta sobremaneira a desmitificação acerca da inexequibilidade dos mecanismos de reintegração social, ainda enxergados como algo utópico e inalcançável.

Portanto, ao desconhecer por completo um mecanismo que poderia de fato apresentar resultados positivos em maior escala, resta a reverberação de um discurso pautado em descrença para com o problema em tela, o qual não ajuda em nada no enfrentamento da questão.

No estado do Rio Grande do Norte, a APAC foi introduzida nas comarcas de Macau e Parelhas, como iniciativa do Programa Novos Rumos na Execução Penal que, por seu turno, incentiva a estruturação e o acompanhamento na aplicação da pena, bem como a implementação de medidas alternativas ao Estado (TJRN, 2016).

Todavia, por enquanto, o município de Macau, por exemplo, inaugurado em 2010, apresenta um CRS com capacidade para apenas 20 (vinte) recuperandos no regime fechado e 06 (seis) no regime semiaberto. Além de uma estrutura precária, a inconsistência nos repasses 
firmados, mediante convênio com o município de Guamaré, dificulta sobremaneira o trabalho com os recuperandos, nos moldes propostos pela FBAC (Federação Brasileira de Associação ao Condenado) (TJRN, 2016).

Atualmente, existem 39 APACs em funcionamento no Brasil, atendendo a 2.800 presos, das quais 34 unidades se encontram em Minas Gerais, onde funciona o centro mais antigo, na cidade de Itaúna, que recebeu seus recuperandos em 1991. As demais APACs se encontram espalhadas nos estados de Espírito Santo, Maranhão e Piauí, além do Rio Grande do Norte (FBAC, 2016).

Ressalta-se, ainda, que enquanto no sistema penitenciário comum a média com a manutenção de um preso é de $\mathrm{R} \$ 1.800,00$ (mil e oitocentos reais), na APAC essa estimativa cai para $\mathrm{R} \$ 1.000,00$ (mil reais). Portanto, tem-se um modelo mais efetivo e menos custoso. $\mathrm{Na}$ APAC, por exemplo, nunca foi registrada uma rebelião, nem mesmo na unidade de Itaúna, hoje com 165 presos, como também nunca foram registrados homicídios ou suicídios (FBAC, 2016).

Desse modo, a expansão e estruturação do método "apaqueano" é iniciativa urgente que deve ser endossada pelas autoridades estatais, aliada a outras medidas responsáveis por promover um regime penal menos segregador e mais humano.

\section{AS NUANCES DA VIOLÊNCIA ESTRUTURUAL EM FACE DA CRISE DO SISTEMA CARCERÁRIO NO RIO GRANDE DO NORTE}

Ultrapassada a discussão em torno da falência da ideologia da ressocialização e a implantação da APAC como representação da teoria social emancipadora dentro do modelo penitenciário norte-rio-grandense, cumpre estabelecer os motivos responsáveis pela manutenção desse quadro de instabilidades para que assim se possa atacar os meios responsáveis pelo resultado final de fragilidade enfrentado pelo sistema.

Introduzindo-se o tema em pauta com uma reflexão de Zaffaroni (2015, p. 15), podese dizer que “"crise' para nós, portanto, é o momento em que a falsidade do discurso jurídicopenal alcança tal magnitude de evidência, que este desaba, desconcertando o penalismo da região". 
Logo, genuinamente, a instabilidade do sistema carcerário brasileiro não condiz com uma crise propriamente dita, no sentido denotativo empregado a tal vocábulo, vez que decorre diretamente de uma opção política operada pelos detentores de poder na sociedade (Estado, mídia, polícia, escola). Dessa forma, “o sentido de 'crise' refere-se a uma brusca aceleração do descrédito do discurso jurídico-penal" (ZAFFARONI, 2015, p. 15).

Em outras palavras, a "crise" remonta a uma insubsistência da ideologia de governo adotada, muito pela falta de diálogo com a própria sociedade e, sobretudo, com os concernidos desse processo.

Assim sendo, necessita-se desmistificar a falácia institucionalizada de que a solução da "crise" neste setor remonta a uma atuação mais ativa do Estado em relação a problemas conjunturais isolados, a exemplo da educação, da distribuição de renda, reformas de lei e do próprio sistema prisional.

Oportunamente, todas essas problemáticas devem ser de fato enfrentadas, em um planejamento a longo prazo; no entanto, não se pode continuar negligenciando a estruturação de uma política criminal crítica, pensada particularmente para o estado e para o próprio país, no que tange ao assunto em pauta. Pois, do contrário, a programação normativa ensaiada pelo discurso jurídico-penal continuará dissociada da realidade.

Destarte, em face a uma ideologia falida, a sanção penal perde todas as funções pensadas em uma justificação externa ou interna, havendo uma "progressiva 'perda' das "penas", as quais se traduzem em "inflição de dor sem sentido", na medida em que são carentes de racionalidade (ZAFFARONI, 2015, p. 13).

Desse modo, as instâncias de poder, junto as agências punitivas, ante ao "esgotamento de ficções gastas" do seu arsenal de ilusões, atuam de forma a manter a coesão de um sistema esfacelado pela sua própria essência, impondo à sociedade mais discursos falaciosos (ZAFFARONI, 2015, p. 12).

Nesse ínterim, destacam-se projetos de lei com ênfase a penas privativas de liberdade mais contundentes ao invés de restritivas de direitos (mais eficazes); construção de prisões, em detrimento à estruturação de medidas alternativas ao cárcere e, por conseguinte, ações de marginalização do preso ao invés da reintegração social.

Com isso, observa-se num discurso jurídico penal falso, de "tolerância zero" com os presidiários, uma violência estrutural encoberta que deve ser compreendida para que seja 
possível reconhecer o verdadeiro agente ativo dessa instabilidade, além do presidiário, socialmente alijado, por seu turno, um dos principais afetados em todo esse panorama.

Perceba-se, assim, que existe uma violência institucionalizada maximizando a violência individual refletida no delito cometido pelo agressor. Por sua vez, o Estado mascara uma política de defesa social, buscando nessa falácia uma forma de se eximir da sua responsabilidade e, com efeito, faz a comunidade acreditar na inexistência dessa violência estrutural, evidenciando a segregação daqueles indivíduos selecionados que servem de "bodes expiatórios" para a mídia (ZAFFARONI, 2015, p. 256).

Nesse fim, a violência estrutural representa mais do que uma violência individual, refletindo um conjunto de omissões responsáveis por marginalizar o indivíduo selecionado, dificultando-lhe o acesso aos benefícios do progresso econômico (GALVÃO; MARTINS, 2013). Segundo Leonardo Boff (2016), é estrutural pois é própria do sistema econômico adotado, o capitalismo, enquanto regime essencialmente perverso, gerador de opressão, eventualmente desdobrando-se em repressão.

\section{AS MAZELAS DO ENCARCERAMENTO EM MASSA}

Considerando-se tudo o que foi exposto até o momento, é importante analisar, mais a fundo, por que o encarceramento em massa não é a medida mais adequada à elucidação dos problemas pertinentes ao sistema carcerário do estado.

Para tanto, far-se-á um estudo comparado com a realidade dos Estados Unidos da América e a implantação do movimento "Law and Order", o qual levou o país ao aumento do número de prisões e, conseguintemente, a um processo de criminalização da pobreza (BAUMAN, 1999).

Na análise de Loic Wacquant (2004), os EUA promoveram uma expansão vertical do sistema, triplicando a sua população carcerária em apenas 15 anos, através do encarceramento de pequenos delinquentes e, particularmente, dos toxicômanos. Desse modo, o "tratamento social da miséria" transformou-se em uma questão penal.

\footnotetext{
${ }^{\star}$ Lei e Ordem.
} 
Nessa linha, o documentário "13 TH”, dirigido por Ava DuVernay e lançado pelo Netflix ${ }^{\S}$ em outubro de 2016, em alusão à décima terceira emenda da constituição americana, responsável por concretizar o fim da escravidão em 1865, traça um paralelo entre o contexto político que propagou a onda do encarceramento em massa nos EUA e as imbricações desse processo com o corporativismo responsável pelo controle do sistema prisional norteamericano (NETFLIX, 2016).

Logo nos primeiros minutos do filme, o telespectador já se defronta com a impressionante estatística de que os EUA abrigam apenas $5 \%$ da população mundial, mas $25 \%$ dos prisioneiros do mundo. Com efeito, mediante a entrevista de acadêmicos, políticos e ex-prisioneiros, o documentário deixa claro os motivos que conduziram essa superpotência econômica mundial a inflar sua população carcerária, passando de 357 mil pessoas, em 1970, para 2,3 milhões em 2014, sendo negros mais de 40\% desse total (O GLOBO, 2016).

Por consequência, o impacto dessa onda de encarceramento foi sentido pelos mais variados países e o Brasil, a seu turno, seguindo o modelo estadunidense, alavancou uma incrível expansão de sua população carcerária que, entre 1995 e 2010, cresceu cerca de 235\%, passando de 148 mil para 496 mil pessoas (VALENTE, 2012).

Nesse pórtico, com o fim da escravidão nos EUA, em verdade, desencadeou-se a implantação de uma espécie de regime escravocrata neoliberal dentro das prisões em que o sistema capitalista passou a coordenar o modus operandi ${ }^{* *}$ do aparelho punitivo.

De acordo com o supracitado documentário, segundo o texto legal da $13^{\mathrm{a}}$ emenda à constituição norte-americana, todos os homens estariam livres, com exceção aos criminosos. Pautado nesse escape legal, as políticas de "Lei e Ordem" e "Tolerância Zero" tornaram-se plataforma de governo dos mais variados candidatos que concorreram à presidência dos Estados Unidos da América (NETFLIX, 2016).

Durante o governo Reagan (1981-1989), por exemplo, intensificou-se o discurso implantado na gestão de Nixon, quanto ao famigerado combate da "guerra às drogas" e, consequentemente, reforçou-se a criminalização da comunidade negra, a qual passou a ser presa em grande escala pelo porte/uso de entorpecentes, sobretudo, maconha (NETFLIX, 2016).

\footnotetext{
$\S$ Provedora global de filmes e séries de televisão via streaming.

*** Modo pelo qual um indivíduo ou uma organização desenvolve suas atividades ou opera.
} 
Algo semelhante se vê no Brasil em que a importação de um discurso opressor de intolerância é responsável por um quadro estatístico no qual o crime é condicionado pela situação socioeconômica, nível educacional e circunstância ética do autor do delito. Nesse cenário, $67 \%$ dos presos brasileiros são de etnia negra, sendo $27 \%$ condenado por tráfico de drogas e $21 \%$ por roubo (SENADO FEDERAL, 2016).

Mas, voltando aos EUA, pode-se dizer que o fundamento de uma política carcerária extremamente rigorosa para com os negros esteve sempre relacionado com a lógica por trás da privatização do sistema prisional. A título de ilustração, a ALEC (American Legislative Exchange Council) $)^{\dagger}$, associação formada por políticos republicanos e corporações econômicas, durante muito tempo foi responsável por influenciar o poder legislativo estadunidense na criação de leis mais severas capazes de endossar a crescente onda de encarceramento no país (NETFLIX, 2016).

Por consequência, conseguia-se um maior contingente de mão de obra escrava dentro dos estabelecimentos prisionais, a seu turno coordenados pelas próprias corporações integrantes desse "organismo atípico de poder", como a CCA (Corrections Corporation of America), GEO Group e o MCT (Management and Training Coorporation) (CORREA, 2016).

Tais corporações, dentre tantas outras que integraram a associação, investem no sistema em troca do trabalho gratuito dos presidiários. Trata-se de uma verdadeira rede econômica que se espalha por todos os lugares, desde o ramo dos esportes (chapéus, uniformes, calçados), passando pela Microsoft, Boeing ${ }^{t+1}$, jeans JCPenney, confeccionado pelos detentos do Tennessee e a famosa marca de lingerie Victoria's Secret (NETFLIX, 2016).

Nesse panorama, praticamente todo projeto de lei impulsionado pela ALEC favorecia um membro coorporativo. O Walmart, por exemplo, maior vendedora de rifles dos EUA e o maior varejista de balas do mundo, antigo membro do Conselho Americano de Intercâmbio Legislativo, foi diretamente favorecido com a criação da lei "Stand Your Ground Law" "Não ceda terreno", a qual sustentava uma ideia de "legítima defesa" e provocou um grande aumento na venda de armas no país (NETFLIX, 2016).

\footnotetext{
† Conselho Americano de Intercâmbio Legislativo.

\# The Boeing Company é uma corporação multinacional norte-americana de desenvolvimento aeroespacial e de defesa.
} 
As leis anti-imigrantes, como a SB1070, do Arizona, também endossadas pela ALEC, evidenciavam o claro objetivo de se criminalizar setores sociais específicos visando a obtenção de lucro que o ingresso dessas pessoas no sistema geraria. De acordo com a referida normativa, implantou-se uma verdadeira política de defesa social, segundo a qual o Estado poderia deter e encarcerar, arbitrariamente, qualquer suspeito que não estivesse portando seus documentos (NETFLIX, 2016).

Dessa maneira, apenas no ano de 2009, de acordo com o relatório anual de finanças disponibilizado pela Nasdaq (National Association of Securities Dealers Automated) ${ }^{\S \S}$, a CCA obteve rendimentos acima de 1 bilhão e 660 milhões de dólares pela administração das prisões e centros de detenção migratória (OTERO, 2011).

Tem-se, assim, uma lógica corporativista que foi evidenciada por Foucault (2002), em Vigiar e Punir, demonstrando-se o vínculo direto entre prisão e fábrica, na discussão sobre a "economia da pena" e a forma como a máxima da "tolerância zero" serve, de fato, ao sistema capitalista, antes mesmo de justificar qualquer fim estritamente criminal.

Portanto, verdadeiramente, a função da pena remonta a uma tripla finalidade, associando alienação, domesticação e contenção do trabalhador através de um mecanismo imperativo de disciplina que se consubstancia com o cárcere e proporciona um subsistema social, mediante uma economia política do corpo a fim de tornar útil a força produtiva absorvida pela instituição (SANTOS, 2005).

Nessa toada, em face à crise instituída pela forte monetização do sistema, aos poucos a ALEC foi perdendo apoio e hoje possui um discurso de gradual desencarceramento, pautando-se em políticas alternativas de controle, a exemplo da ampliação dos mecanismos de monitoramento dos condenados através de chips eletrônicos, com os quais certamente continuariam a lucrar (NETFLIX, 2016).

Por seu turno, em agosto do corrente ano, o Departamento de Justiça dos Estados Unidos declarou seu interesse em estatizar as prisões federais do país, considerando o relatório realizado pela divisão de fiscalização do órgão, segundo o qual as prisões privadas são mais perigosas (em termos de agressões, motins e contrabandos) e menos propiciadoras à reintegração social do apenado (CORREA, 2016).

\footnotetext{
§§ Associação Nacional de Corretores de Títulos de Cotações Automáticas - mercado de ações automatizado norte-americano onde estão listadas mais de 2800 ações de diferentes empresas, em sua maioria de pequena e média capitalização.
} 
Com isso, vê-se a desconstrução sensível, mas progressiva, de um discurso consolidado há mais de 40 anos que, de acordo com Martin Horn, especialista em justiça criminal, professor do John Jay College of Criminal Justice e ex-chefe do departamento de correções e liberdade provisória da cidade de Nova York, decorre da mudança de mentalidade e postura da própria sociedade, a qual tem apresentado grandes objeções à filosofia lucrativa em torno das prisões privadas (CORREA, 2016).

Nesse sentido, propugna-se a difusão de uma política desencarceradora, pautada em "programas mínimos de ressocialização", sobretudo no que tange às penas alternativas à prisão, sob o escopo de encarar a problemática em torno do crime de forma mais pragmática, social e humana.

\section{A IMPLEMENTAÇÃO DA JUSTIÇA RESTAURATIVA COMO POSSÍVEL SAÍDA PARA A CRISE VIVENCIADA NO SISTEMA CARCERÁRIO NORTE- RIOGRANDESE}

Enquanto alternativa à crise do sistema penitenciário então discutida, faz-se forçoso admitir uma corresponsabilidade entre o Estado, a comunidade e o indivíduo, a fim de que as falhas estruturais referentes ao problema possam ser superadas.

Na visão de Howard Zehr (2008, p. 168): “A lente através da qual enxergamos determina o modo como configuraremos o problema e a "solução". Portanto, considerando que o crime ainda hoje é enxergado através de uma "lente retributiva", as consequências decorrentes dessa interpretação levam à insatisfação pela inalcançabilidade dos resultados ideologicamente almejados.

Pois, não há como se falar em justiça como retribuição ao mal cometido mediante o delito se, no decorrer do processo, as vítimas são negligenciadas sob a tentativa falida de se responsabilizar o ofensor e coibir o crime. Desse modo, instala-se o sentimento de impotência e desolamento acerca do sistema penal que se reflete em uma crise generalizada (ZEHR, 2008, p. 167).

Dessa forma, enquanto não houver uma mudança no modo de se compreender e, consequentemente, de se gerir o problema, todas as soluções alcançadas nessa seara, de maneira isolada, serão insuficientes. Recuperando as palavras de Howard: "Para achar a saída 
desse labirinto, teremos que procurar mais além de simples penas alternativas. Teremos que buscar formas alternativas de ver o problema e a solução" (ZEHR, 2008, 169).

Com efeito, o que o autor propõe em suas reflexões é, em verdade, a transição da justiça retributiva para a justiça restaurativa, uma "mudança de lentes" que implica não em uma mudança de paradigma, mas em uma nova maneira de se interpretar a situação. Até porque, como o próprio Howard coloca em seus escritos, a alteração de um paradigma é algo muito mais complexo que requer uma interação bastante aplicada entre todos os fatores pertinentes ao contexto da mudança desejada. Seria algo semelhante aos programas máximos de ressocialização elencados por Santiago (1989), os quais, igualmente, são inviáveis à realidade do sistema carcerário norte-rio-grandense.

Por outro lado, trabalhar com programas mínimos e com uma nova abordagem de resolução do conflito pode de fato surtir resultados satisfatórios que sequer são imaginados. Isso porque, trabalhando com uma verdade comum, porém inevitável, o anseio do povo no assunto ora em tela é uníssono e paradoxalmente superficial: frear o desenvolvimento da criminalidade e suavizar o sentimento de insegurança gerado pela violência individual relacionada à ação delituosa.

Paradoxal, pois reducionista enquanto resposta programada para a problemática em questão, mas ao mesmo tempo difícil de se conseguir resolver. Assim, surge a necessidade de se compartimentar as variadas soluções praticáveis, aplicando-as pelos mais diversos ângulos de execução.

Desta feita, a justiça restaurativa serve verdadeiramente ao ideal da reintegração do apenado, na medida em que atua, dentro do possível, na reconstrução de laços rompidos pelo ilícito cometido e na recuperação de vínculos do condenado com a sociedade e, sobretudo, com a sua própria família. Pois, tal qual colocado por Baratta (2016), é impossível pensar em reintegração se o modus operandi para tanto é a exclusão e a marginalização.

Apesar de o autor abordar a justiça restaurativa de forma mais ampla, até mesmo para os crimes de homicídio, trazendo, aqui, a abordagem para a realidade do estado, em que a maioria dos delitos cometidos são de cunho patrimonial ou envolvem a questão das drogas, apresentar uma possibilidade de reconciliação entre os agentes reais desse processo criminológico (vítima e agressor), poderia surtir efeitos positivos que a mera justiça retributiva não apresenta. 
Tal qual explicado por Walter Nunes da Silva Junior (2019, nota 135), "a ideia da justiça restaurativa é o estabelecimento de um sistema complementar ao processo criminal, a fim de conceber programas de segurança e auxílio não apenas às vítimas, mas igualmente às testemunhas e aos acusados".

No entanto, de fato, propugna-se, nessa reforma processual criminal, uma atenção especial as vítimas, que, por muito tempo, foram tratadas de forma secundária. Objetiva-se, assim, sua participação mais ampla no processo, com a implementação de ações sociais que visem ampará-las e reparar ou diminuir os malefícios do ilícito causado (SILVA JUNIOR, 2019).

Trata-se de matéria regulamentada pela ONU com a Declaração dos Direitos Fundamentais da Vítima, de 1985, embrião do que hoje se difunde como vitimologia. Isso porque, não se adota mais a ideia de que a resolução do processo possa ser efetivamente satisfatória, sem a participação do ofendido e a atuação do Estado na minoração dos prejuízos causados.

Atualmente, no Rio Grande do Norte, o projeto de justiça restaurativa vem sendo institucionalizado dentro do Tribunal de Justiça do estado, desenvolvido pelo juiz José Dantas de Paiva. Segundo o magistrado, o programa está $40 \%$ concluído, tendo ocorrido cursos de formação de facilitadores com uma equipe técnica da Associação de Juízes do Rio Grande do Sul por intermédio da Escola da Magistratura do RN (ESMARN) (PORTAL DO JUDICIÁRIO, 2016).

Por conseguinte, o projeto vem sendo testado primeiramente nos Juizados Especiais Criminais. Posteriormente, o objetivo é também aplicá-lo na Justiça da Infância e da Juventude, para crimes de menor potencial ofensivo, até que seja possível implantar essa metodologia em processos mais complexos (PORTAL DO JUDICIÁRIO, 2016).

Portanto, seguindo a linha de outros estados do país que já adotaram a implementação desse método, a exemplo de São Paulo e do Rio Grande do Sul e os quais, com efeito, vêm colhendo resultados positivos desde então, o Rio Grande do Norte tem a perspectiva de neste ano (2019) conseguir grande progresso, alcançando-se um menor índice de reincidência e até mesmo a desjudicialização de alguns processos (PORTAL DO JUDICIÁRIO, 2016).

Desta feita, vê-se na fomentação de iniciativas como essas uma saída verdadeiramente legítima e palpável para o problema vivenciado no estado nessa seara, de 
modo que não se justifica a insistência em ideologia falidas quando existem outros mecanismos viáveis à resolução da problemática.

\section{CONCLUSÃO}

Concebendo-se que a crise engendrada no sistema carcerário norte-rio-grandense não possui caráter de transitoriedade e, em verdade, é fruto de uma violência estrutural perene, surge-se a necessidade de se pensar em soluções capazes de promover a superação da instabilidade consolidada nesse setor.

Desse modo, o estudo em análise buscou demonstrar que a polêmica em torno da falência da ideologia da ressocialização implica necessariamente na superação de tal conceito. Portanto, faz-se mister discutir formas de melhor adequar tal instituto à realidade do estado, a fim de que não se recaia em falácias idealistas impossíveis de serem cumpridas, conforme se tem hoje em dia. Desta feita, a participação do ente estatal na configuração de uma política criminal pensada particularmente para o sistema penitenciário do Rio Grande do Norte é condição sine qua non ao enfrentamento da questão.

Assim, buscando-se azo na criminologia clínica e nas ideias trazidas pela terapia social emancipadora, aplicada através da APAC, entende-se ser possível o processo de recuperação do preso, na medida em que lhe são oferecidas possibilidades de mudança da sua autopercepção a fim de se eliminar o estigma negativo introjetado pelo cárcere.

Portanto, torna-se imprescindível criar um canal de diálogo entre o preso, o Estado e a comunidade, para que as suas necessidades sejam levadas em consideração e, por conseguinte, variadas crises não se manifestem enquanto resistência à segregação imposta pela conjuntura político-social hodiernamente instaurada.

\section{REFERÊNCIAS}

ALVES, Fábio Wellington Ataíde. Laranja mecânica (parte 1). BCEJ. Ciências criminais. 2016. Disponível em: http://bcej.com.br/ciencias-criminais/laranja-mecanica-parte-1/. Acesso em: 07 abr. 2019.

Laranja mecânica (parte 02). BCEJ. Ciências criminais. 2016. Disponível em:

http://bcej.com.br/ciencias-criminais/laranja-mecanica-parte-1/. Acesso em: 07 abr. 2019. 
BARATTA, Alessandro. Resocialización o control social: por un concepto critico de reintegración social del condenado. Seminario Criminologia Crítica y sistema penal. Tradução de Mauricio Martínez. Lima, 1990, p. 3. Disponível em:

http://www.inau.gub.uy/biblioteca/Resocializacion.pdf. Acesso em: 21 abr. 2019.

Uma abordagem crítica da "reintegração social" do sentenciado. Universidade Federal de Saarland, R.F.A. Disponível em:

http://www.juareztavares.com/textos/baratta_ressocializacao.pdf. Acesso em: 21 abr. 2019.

BARBOSA, Rafael. Penitenciária de Alcaçuz completa 18 anos distante da ideia original.

Novo. Polícia. 2016. Disponível em: http://novojornal.jor.br/policia/penitenciaria-de-alcacuzcompleta-18-anos-distante-da-ideia-original. Acesso em: 21 abr. 2019.

BAUMAN, Zygmunt. Globalização: as consequências humanas. Rio de Janeiro: Zahar, 1999.

BITENCOURT, Cezar Roberto. Tratado de direito penal. 17 ed. São Paulo: Saraiva, 2012.

BURGESS, Anthony. Laranja mecânica. Tradução de Fábio Fernandes. São Paulo: Aleph, 2012 .

CONECTAS. Direitos Humanos. Mapa das prisões. Novos dados do Ministério da Justiça retratam sistema falido. 2014. Disponível em: http://www.conectas.org/pt/noticia/25378mapa-das-prisoes. Acesso em: 13 abr. 2019.

CORREA, Alessandra. Por que os EUA deixam de usar prisões privadas. BBC Brasil. 2016. Disponível em: http://www.bbc.com/portuguese/internacional-37195944. Acesso em: 25 abr. 2019.

FBAC. Fraternidade brasileira de assistência aos condenados. Filosofia da APAC. 2016. Disponível em: http://www.fbac.org.br/index.php/pt/filosofia-da-apac. Acesso em: 03 abr. 2019.

FOUCAULT, Michel. Vigiar e punir: nascimento da prisão. 25. ed. Trad. Raquel Ramalhete. Petrópolis: Vozes, 2002. 
LOMBROSO, Cesare. O homem delinquente. Trad. Sebastião José Roque. São Paulo: Ícone, 2013.

MARTINO, Natália. Índice de reincidência no crime é menor em presos das Apacs. BBC Brasil. 2014. Disponível em:

http://www.bbc.com/portuguese/noticias/2014/03/140313_prisoes_apac_nm_lk. Acesso em: 13 abr. 2019.

MUÑOZ CONDE, Francisco; HASSEMER, Winfried. Introdução à criminologia. Tradução de Cíntia Toledo Miranda Chaves. Rio de Janeiro: Lumen Juris, 2008.

O GLOBO. Documentário '13 th' traça paralelo entre escravidão e prisões em massa de negro dos EUA. 2016. Disponível em: http://oglobo.globo.com/cultura/filmes/documentario13th-traca-paralelo-entre-escravidao-prisoes-em-massa-de-negros-dos-eua-20234360. Aceso em: 23 abr. 2019.

OTERO, Silvia. Cárceres dos Estados Unidos: imigrantes são negócios. Sociedade. Carta Capital. 2011. Disponível em: http://www.cartacapital.com.br/sociedade/carceres-dosestados-unidos-imigrantes-sao-negocio. Acesso em: 25 abr. 2019.

OTTOBONI, Mário. Vamos matar o criminoso? Método APAC. São Paulo: Paulinas, 2001.

Seja solução, não vítima! São Paulo: Cidade Nova, 2004.

PORTAL DO JUDICIÁRIO. Justiça Restaurativa conta com a atuação de 25 facilitadores no RN. 2016. Disponível em: http://www.tjrn.jus.br/index.php/comunicacao/noticias/10047justica-restaurativa-conta-com-atuacao-de-25-facilitadores-no-rn. Acesso em: 03 abr. 2019.

SÁ, Augusto Alvino de. Sugestão de um esboço de bases conceituais para um sistema penitenciário. Escola de administração penitenciária do estado de São Paulo. 2007. Disponível em: http://www.sap.sp.gov.br/download_files/reint_social/apresentacao/sugestao_esboco.doc>. Acesso em: 21 abr. 2019.

SANTIAGO, Mir Puig. Que queda en pie de la resocializacion? Eguzkilore. Cuarderno del Intituto Vasco de Criminologia. Sán Sebastian, n. 2, 1989. Disponível em: file:///C:/Users/Caio/Downloads/queda-en-pie-de-la-resocializacion-PUIG.pdf. Acesso em: 17 mar. 2019. 
SANTOS, Juarez Cirino dos. 30 anos de vigiar e punir (Foucault). $11^{\circ}$ seminário internacional do IBCCRIM. São Paulo, 2005 Disponível em:

file://C:/Users/Caio/Downloads/SANTOS,\%20Juarez\%20Cirino\%20dos.\%2030\%20ANOS \%20DE\%20VIGIAR\%20E\%20PUNIR.pdf. Acesso em: 25 abr. 2019.

SENADO FEDERAL. Perfil de pessoas presas no Brasil. Em discussão. Infográficos da edição. 2016. Disponível em: http://www12.senado.leg.br/emdiscussao/edicoes/privatizacaode-presidios/infograficos-da-edicao. Acesso em: 24 abr. 2019.

SILVA JÚNIOR, Walter Nunes da. Curso de direito processual penal: Teoria (constitucional) do processo penal. 3. ed. Revista, atualizada e ampliada. Natal: OWL, 2019, prelo.

TJRN. Novos rumos da execução penal. Programas e projetos. Disponível em: http://www.tjrn.jus.br/index.php/administrativo/programas-e-projetos/44-programas-eprojetos/1200-novos-rumos-2. Acesso em: 01 abr. 2019.

UM SONHO DE LIBERDADE. Direção de Frank Darabont. Produção de David V. Lester. Estados Unidos da América: Castle Rock Entertainment, 1995. (142 min.), son. color. Legendado

VALENTE, Rodolfo de Almeida. O mundo encarcerado. Revista crítica do direito. São Paulo, n. 2, v. 41, out-nov. 2012. Disponível em:

https://sites.google.com/a/criticadodireito.com.br/revista-critica-do-direito/todas-asedicoes/numero-2-volume-41/o-mundo-encarcerado. Acesso em: 10 abr. 2019.

WACQUANT, Loic. As prisões da miséria. Trad. André Telles. Rio de Janeiro: Zahar, 2004.

ZAFFARONI, Eugênio Raúl. A questão criminal. Tradução de Sérgio Lamarão. Rio de Janeiro: Revan, 2015

Em busca das penas perdidas: a perda de legitimidade do sistema penal. Tradução de Vânia Romano Pedrosa; Almir Lopes da Conceição. 5. ed. Rio de Janeiro: Revan, 2015.

ZEHR, Howard. Trocando as lentes: um novo foco sobre o crime e a justiça restaurativa. Trad. Tônia VanAcker. São Paulo: Palas Athena Editora, 2008. 
13TH. Direção de Ava Duvernay. Produção de Spencer Averick. Música: Jason Moran. Estados Unidos da América: Netflix, 2016. (100 min.), son., color. Legendado. 